\title{
Narrative Serious Game Mechanics (NSGM) - Insights into the narrative-pedagogical mechanism
}

\author{
T. Lim ${ }^{1}$, S. Louchart ${ }^{1}$, N. Suttie ${ }^{1}$, J. Baalsrud Hauge 2 , I.A. Stanescu ${ }^{3}$, I M. Ortiz ${ }^{4}$, P.

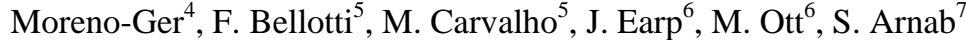 \\ ${ }^{1}$ Heriot-Watt University, Riccarton, Edinburgh EH14 4AS, Scotland, UK \\ ${ }^{2}$ Bremer Institut für Produktion und Logistik (BIBA), Germany \\ ${ }^{3}$ National Defence University "Carol I", Bucharest , 50662, Romania \\ ${ }^{4}$ Complutense University, Madrid 28040, Spain \\ ${ }^{5}$ University of Genoa, 16145 Genova, Italy \\ ${ }^{6}$ Consiglio Nazionale delle Ricerche (CNR), 16149 Genova, Italy \\ ${ }^{7}$ Serious Games Institute, Coventry University, Coventry CV1 2TL, UK \\ \{t.lim,s.louchart,n.suttie\}@hw.ac.uk, baa@biba.uni-bremen.de, ioana.stanescu@adlnet.ro, \{imartinez, \\ pablom\}@fdi.ucm.es, \{franz, Maira.Carvalho\}@elios.unige.it, \{jeff,ott $\} @$ itd.cnr.it, \\ s.arnab@coventry.ac.uk
}

\begin{abstract}
Narratives are used to construct and deconstruct the time and space of events. In games, as in real life, narratives add layers of meaning and engage players by enhancing or clarifying content. From an educational perspective, narratives are a semiotic conduit for evoking critical thinking skills and promoting knowledge discovery/acquisition. While narrative is central to Serious Games (SG), the relationships between gameplay, narrative and pedagogy in SG design remain unclear, and narrative's elemental influence on learning outcomes is not yet fully understood. This paper reports efforts to shed light on these issues by advancing a purpose-processing methodology that aims to support the mapping of SG design patterns and pedagogical practices, allowing designers to create more meaningful SG. In the case of narrative, the intention is to establish whether Narrative Serious Game Mechanics (NSGM) provide players with opportunities for reasoning and reflective analysis that may even transcend the game-based learning environment.
\end{abstract}

\section{Introduction}

Discourse, the narration aspect of storytelling plays an important role in defining a narrative environment through careful descriptions of both context and roles, ultimately motivating a player (in the case of Digital Games) to intervene and act. In this motivational process (often described as exposition), extensively documented by Propp [1], Campbell [2] and many others [3-6], the main protagonists are exposed to a sequence of events that motivate them to act, essentially embarking on a narrative journey. Narrative creates the player's desire to achieve the goals and see what 
happens next, and it achieves these goals through three important techniques: immersion, reward, and identification.

Chatman [7] differentiated between story and discourse, story representing the actual elements present in a story (content) and discourse the narration of a story and how it is presented to an audience (form). This distinction is relevant to the study of narrative mechanics in Serious Games (SG) because story elements are tangible entities that can be analysed at a structural level, while discourse helps to shape an SG experience. For instance, if the purpose of an SG is to induce an affective response towards the negative aspects of a certain behaviour, the form and tone/aesthetics of the discourse (genre, filmography, graphic presentation, realism) are (or should be), in keeping with the main purpose of the SG, independent of the actual narrative content conveyed.

Research has revealed two key challenges in this area, namely the transition between an SG's underlying instructional design and its actual design implementation [8], and the insolvency in mapping game design patterns onto relevant pedagogical patterns [9]. Discussions carried out within the game mechanics workshop organised during the $2^{\text {nd }}$ Alignment School of the EU co-funded Game and Learning Alliance Network of Excellence (GALA NoE) have concluded that the aforementioned transition lacks methodology and customers commissioning SGs are forced to make a leap of faith when gauging a SG developer's capacity to deliver a game that will achieve the desired learning outcomes. This echoes Wexler's [10] evidence on how the growing complexity of SGs impact the way educators use SGs in teaching.

This paper presents a purpose-processing methodology that is used in a preliminary effort to probe narrative discourse in SG and is ultimately intended as a means for investigating how serious game design patterns map with pedagogical practices. To redress the dependence on SG developers in the creation/adaptation of SG content, a story-writing process based on narrative metaphors is also reported.

\section{Serious games design and narrative meaning making}

Changes in media technology transform how "societies" are constructed [11]. SGs are increasingly being seen as new ways of learning, and the subjective meanings given to elements of game architecture can result in players having a very different view about the game space. This is a key concern for SG designers, as the interrelationships between the motivational aspects of narrative game mechanics and gameplay style may not be fully appreciated.

Games with narrative elements represent genre in a multidimensional manner because they consist of a narrative genre on the one hand and a gameplay genre on the other. Games often share a common gameplay genre but have different narrative genres (two adventure games might share similar gameplay, but one might focus on history, while the other on space discovery). Similarly, two games can share the same narrative genre but have a radically different gameplay (a first person shooter and an adventure game). This increases the complexity of the issues involved when addressing game narratives. 
Narrative is an area where definitions are still being formulated. Lack of clear examples of great game narratives is another issue that requires attention, especially since SG is a young medium and narrative comparisons to best novels, films, and plays often leaves games seeming slightly deficient. There are a lot of key problems in game design that need to be solved, and this limits the kinds of stories that can be told [12]. Great history stories can be told and learners may enjoy them, but the essential tension between the freedom of the player and the constraints of narratives places severe limits on what can be achieved at the present time. There is a conceptual gap between the conventions of digital games and those of non-theatrical drama that need to be addressed.

Crucially, the narrative cannot be fully appreciated if learners cannot grasp the gestalt of semiotic communication. Lastly, players may play in a style that the game was not designed for. Ideally, the SG learner should develop and take forward the epistemic values posed by a game's narrative mechanics.

Tochon's [13] position on educational narrative being tied to the philosophy of Signs and Meanings has deep implications for the way narrative contributes to educating the individual. People acquire identity from and through discourse, not from life but from the stories they collectively construct from events. This aligns with constructivism, the dominant learning theory over the last decade. Herein lays the challenge for the SG developer: to pragmatically translate the many levels of abstractions for knowledge construction such that the epistemological underpinnings are a process of instruction [14].

\section{The semiotic levels of narratives in games}

There are various formats and strategies for integrating narrative and story elements in educational games. Regardless of the mode of interaction with the story and narrative elements, or with the implemented substrate, the fundamental application of narrative is to make meaning of temporal events and relationships [15]. Lindley [16] identified five semiotic levels (or levels of meaning) in narratives, and establishes a relation with the semiotic levels of computer games. Narration becomes the instantiation of an underlying model or simulation in video games, while in traditional media the narration is the instantiation of a story or plot. The model in games usually defines the story implicitly, as a relationship between different elements in the system. Recent AAA productions such as Heavy Rain (Quantic dreams), the Uncharted series or The Last of us (both by Naughty dog) have deliberately shifted this relationship towards cinematic values and the story/narration aspect but this current trend amongst large digital game production does not apply (as of yet) to the vast majority of SGs.

Beyond the content manifested in narratives, structural semiotics is invaluable for discovering the underlying organization of phenomena [17]. SGs, by nature, are not always topics of choice for players and very often do not reflect heavily on the themes and interests proposed by commercial digital games (non SGs). Whilst some elements of motivation might come from elsewhere (workplace, therapy, education, recommendation, etc.), it is possible the motivating role played by narratives and the 
discourse in particular, is crucial to the success of an SG intervention. The hypothesis here is that narratives offer a gateway for learners to combine reflective analysis and explore connotative meanings with other learning tools. Through the study of narrative in SG context, one could potentially assess whether game design patterns can be mapped (at least at a high-level of abstraction) with pedagogical practices.

\section{Defining Narrative Serious Game Mechanics (NSGM)}

According to Harrell [18] many popular narrative experiences have been turned into computer games, but such games are not actually narrative at all. In addition, very few provide the degree of user interaction required for dynamic generation of narrative meaning. One should also note Leymore's [19] caveat on the difficulties in seeing beyond surface features of explicit, structurally organised text/code.

Through narrative discourse, it is possible to identify the generic principles and patterns of composition, and to reveal an underlying structure common to many different SG narratives. The objective is to discern the possible relations between the elements of the narrative/pedagogy/game design triad, essentially the narrativepedagogy implications. These relations operate within four analytical categories: narrative purpose, narrative process and instance, narrative structure and pedagogical implication. These categories are described in detail in the next sections in relation to NSGM.

To establish the cause and effect of designed narration in SG, the authors have developed the concept of Narrative Serious Game Mechanics (NSGM). A NSGM is identified in a game design when aspects of narrative/storytelling such as dialogue, plot events or character actions/behaviours are purposely adopted to achieve specific and identified pedagogical outcomes. A NSGM is represented by a narrative element which directly contributes to or indirectly supports identified learning outcomes as part of a successful SG gaming experience. The definition is purposely broad as it needs to encompass the innovative ways in which narrative plays a role in SG design

The authors are currently investigating NSGM as part of their SG research in GALA NoE. The general aim is to map prevailing characteristics (patterns) of narrative mechanisms and shed light on the potential benefits of associated pedagogic practices. This is being pursued through both top-down (theoretical) and bottom-up (analytical) investigation, an approach which should limit possible blurring of the boundaries between SGMs and allow the identification of a wide range of creative approaches adopted by SG designers.

\section{A Purpose, Process and Structure schemata}

To establish a NSGM trace it is important not only to investigate the purpose for narrative elements, but also their pedagogical context. Process entails the episodic nature of storytelling/narratives. A multi-layered approach that includes the individual, smaller story elements within the various interactive activities of a SG narrative is taken into account towards identifying NSGM. Narrative structures are 
based on linguistics approaches, linking theories on literature, anthropology and sociology. To extract a narrative-pedagogy association, there is a need to identify recurrent aspects such as the relationships between both protagonists and the narrative environment and the necessity for conflict, be it openly towards another (person to person), environmental (person to machine) or internal (person to self) [20].

Table 1. Establishing the purpose of NSGM

\begin{tabular}{|l|l|l|l|}
\hline Type of NSGM & Description & Game purpose & SG purpose \\
\hline $\begin{array}{l}\text { Exposition: the } \\
\text { purpose of the }\end{array}$ NSGM & $\begin{array}{l}\text { What is the } \\
\text { overall function of } \\
\text { the NSGM? }\end{array}$ & $\begin{array}{l}\text { What function articulates or } \\
\text { progresses the game? From the } \\
\text { player's perspective, what } \\
\text { function does this NSGM play? }\end{array}$ & $\begin{array}{l}\text { Pedagogically, } \\
\text { learning outcomes or } \\
\text { processes are related to this } \\
\text { NSGM? }\end{array}$ \\
\hline $\begin{array}{l}\text { Discourse: the } \\
\text { form of the } \\
\text { NSGM }\end{array}$ & $\begin{array}{l}\text { What form does it } \\
\text { take and how is it } \\
\text { represented? }\end{array}$ & $\begin{array}{l}\text { How are these functions } \\
\text { concretely represented in the } \\
\text { game? }\end{array}$ & $\begin{array}{l}\text { How does the form (style, } \\
\text { pace etc.) of this NSGM } \\
\text { contribute to learning? }\end{array}$ \\
\hline
\end{tabular}

Tables Table 1 and Fehler! Ungültiger Eigenverweis auf Textmarke. are used to establish and trace the modus operandi of SG narratives. In this manner, the relationship between tangible narrative components and tangible activities or information within a SG game sequence can be documented, as can the events that directly impact player activity (from a pedagogical perspective) and those that do not but still play a supporting role. This also allows the epistemic/semiotic mechanism and value to be established.

Table 2. Establishing Process and Structure within NSGM

\begin{tabular}{|c|c|c|c|c|}
\hline NSGM Experience & NSGM Process & Narrative Element & Description & Impact \\
\hline $\begin{array}{l}\text { Pre, during and post: } \\
\text { event directly involving } \\
\text { player interaction with the } \\
\text { SG, or sequence where the } \\
\text { player is not engaged in } \\
\text { active game-like } \\
\text { interaction with the SG, } \\
\text { i.e., sequence of tasks / } \\
\text { activities related to the } \\
\text { NSGM occurrence. }\end{array}$ & $\begin{array}{l}\text { Process Step: } \\
\text { Chronology of } \\
\text { activities and } \\
\text { tasks related to } \\
\text { the NSGM. } \\
\text { Describes what } \\
\text { comprises this } \\
\text { step and its } \\
\text { various } \\
\text { elements. }\end{array}$ & $\begin{array}{l}\text { Structure: Describes } \\
\text { the mechanics of } \\
\text { activity or } \\
\text { information } \\
\text { communicated to the } \\
\text { player (information } \\
\text { element, invitation } \\
\text { to act, feedback, } \\
\text { information } \\
\text { communication, } \\
\text { etc.) }\end{array}$ & $\begin{array}{l}\text { Describes the } \\
\text { actions of the } \\
\text { player or the } \\
\text { game in this } \\
\text { phase of the } \\
\text { process. }\end{array}$ & $\begin{array}{l}\text { Describes } \\
\text { the impact of } \\
\text { the step on } \\
\text { both the SG } \\
\text { experience } \\
\text { and the } \\
\text { learning } \\
\text { outcome } \\
\text { both directly } \\
\text { and } \\
\text { indirectly }\end{array}$ \\
\hline
\end{tabular}

Taken together, NSGM form a conceptual/structural layer and typically comprise combinatorial GMs. This is exemplified in Fehler! Verweisquelle konnte nicht gefunden werden. below, which illustrates a mapping of the SG GoVenture AnyBusiness (GVAB) [21]. The Learning Mechanic and Game Mechanic levels are drawn from earlier work produced by some members of the present authoring team [22]. This mapping shows where NSGM reside in GBAV and how they bridge ludic content and learning mechanisms.

These mechanics layers can also be thought of as fibrous, mechanics-studded strands that are interlaced in different manners to form the fabric of SG design. The single mechanics on the different strands may overlap at some points in the weave to form a single node jointly serving learning, gameplay and narrative purposes. In other cases, the strands themselves may be tightly braided and bound so that the individual mechanics they bear are interlocked in a sequence or pattern. 


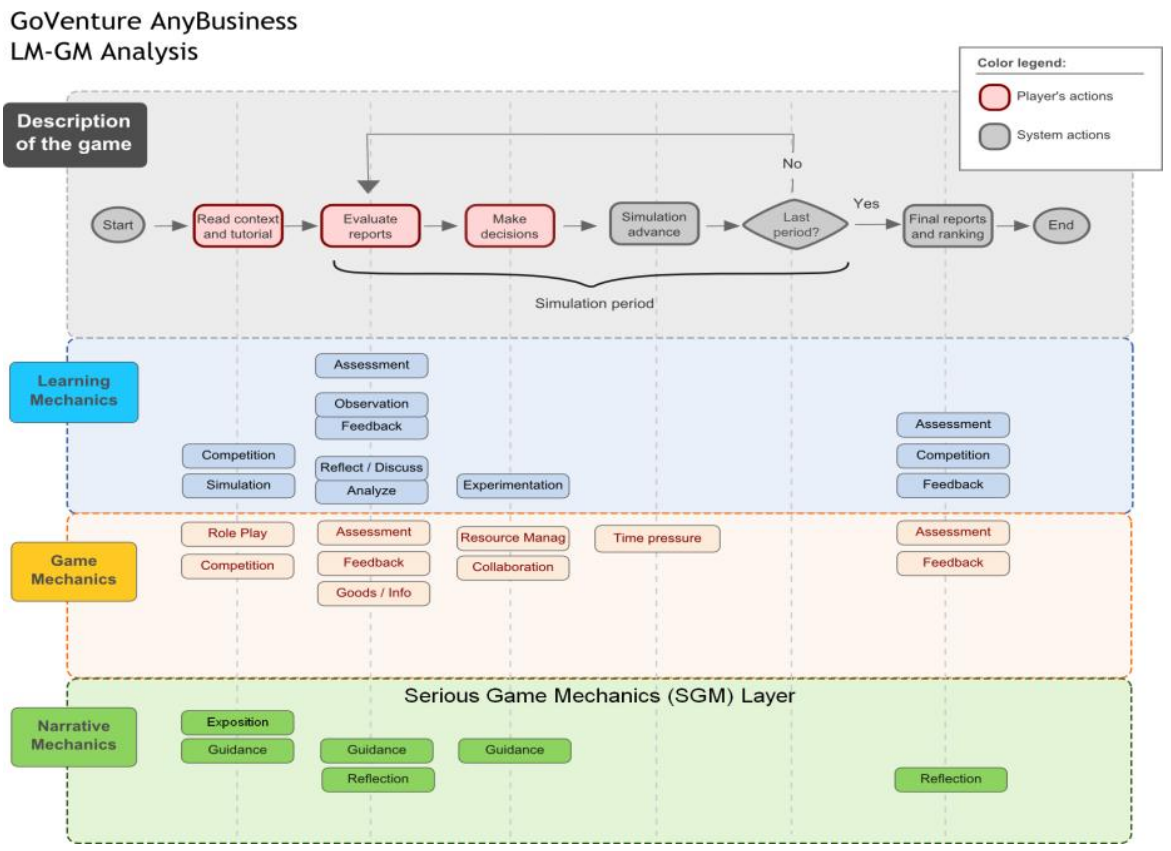

Fig. 1. NSGM mapping of Go Venture AnyBusiness.

\section{NSGM association with pedagogy}

At the most basic level, narrative exposition (NE) together with narrative discourse (ND) sets the scenario of the SG. From the pedagogical perspective it introduces the domain area and the learning contents that the player will interact with as part of the SG-based learning experience. Critically, NE is central to how the SG simulates a context/situation. It is also the gateway to an immersive experience; it draws the player into an enticing, non-threatening game world that (amongst other things) offers the promise of a fruitful learning experience.

Any learner-centred approach must include suitable and timely support for the learner. SGs must provide (or at least allow for) guidance whenever the player perceives the need for further information, specific input, clarification, decisionmaking advice, etc. Pedagogically speaking, when the perceived need concerns a gap in domain-related knowledge, such support falls within the sphere of the Zone of Proximal Development. Thus, where guidance is contextualized within the narrative space and made available via interpersonal interaction (with a NPC), it could be associated with experiential learning and to some extent with Social Constructivism $[23,25]$. On-demand guidance can also be regarded as learner scaffolding, which is the third of the six phases of cognitive apprenticeship, following coaching. In cognitive apprenticeship, on-demand support is a feature of a relatively advanced stage in the learning process, when direct support is diminishing and learner independence is strengthening in a relationship of inverse proportionality. 
Learning approaches, both in a cognitivist and constructivist perspective, place particular emphasis on reflection as a means for constructing meaning, whether at personal or social level. As well as engaging the player, the narrative also needs to be suitably paced and balanced so as to foster reflection. From a cognitive viewpoint, reflection necessarily entails a certain detachment from narrative flow, a loosening of the narrative reins as it were. This mechanic is critical for balancing the ludic-learning dichotomy of SG and hence of SGs' efficacy as learning environments. This balance should be easier to attain, and maintain, when the reflection mechanic is implemented in a way that resonates with the narrative flow.

\section{NSGM association with pedagogical practice}

The picture of narrative components in SGs that emerges from the authors' case studies is similar to that in entertainment games. This poses a problem, as it hinders identification of the narratives' relationship with pedagogy and educational purposes (as reflected by Harrell [18]). However, the adopted purpose-processing method revealed that there is a distinct lack of consideration for drama in the eight SGs studied. This is interesting point to note since narrative and storytelling were intended as framing devices for capturing and maintaining player interest/motivation.

Table 3. Analysis of narrative-pedagogical implications in the GVAB game and the potential benefits of associated pedagogic practices.

\begin{tabular}{|c|c|c|}
\hline NSGM - Type & Description of practice & Pedagogical implications \\
\hline $\begin{array}{l}\text { Exposition: To } \\
\text { introduce and } \\
\text { frame the } \\
\text { world to } \\
\text { engage the } \\
\text { audience. }\end{array}$ & $\begin{array}{l}\text { Text-based information push that } \\
\text { presents game scenario / narrative: } \\
\text { overall game mission, player role, } \\
\text { objectives, environment features. }\end{array}$ & $\begin{array}{l}\text { Introduces the learning contents and establishes gameplay } \\
\text { motivation, which should be aligned and entwined with } \\
\text { learning objectives and task/s. Only embodies experiential } \\
\text { learning to the degree where information push is } \\
\text { appropriately contextualized in the narrative and involves } \\
\text { some interactivity/simulated experience, e.g. through } \\
\text { interaction with NPC. }\end{array}$ \\
\hline $\begin{array}{l}\text { Guidance: } \\
\text { Narrative } \\
\text { elements to } \\
\text { drive the player } \\
\text { into exploring } \\
\text { the world or } \\
\text { interacting with } \\
\text { Non-Player } \\
\text { Characters } \\
\text { (NPC) or } \\
\text { fellow players. }\end{array}$ & $\begin{array}{l}\text { On-demand consultation of an } \\
\text { information source to facilitate } \\
\text { navigation and gameplay, support } \\
\text { decision making, provide clarification, } \\
\text { help unroll the narrative, etc. Guidance } \\
\text { may be generic or personalized } \\
\text { (related to performance). } \\
\text { Consultation is often } \\
\text { contextualized to fit the } \\
\text { game/narrative scenario, e.g. via NPC } \\
\text { or simulated messaging. This is a key } \\
\text { to game environment authenticity and } \\
\text { represents essential scaffolding of the } \\
\text { gaming/learning experience. }\end{array}$ & $\begin{array}{l}\text { To be effective, any learner-centred approach must } \\
\text { include suitable and timely support for the learner. As } \\
\text { effective agents of learner-centred experiences, SGs should } \\
\text { provide such support whenever the player perceives the } \\
\text { need for further information, specific input, clarification, } \\
\text { decision-making advice, etc. In a wider sense, when the } \\
\text { perceived need regards a gap in domain-related knowledge, } \\
\text { the support falls within the Zone of Proximal Development; } \\
\text { so if implemented as part of interaction with NPC, such } \\
\text { support could be associated with Social Constructivism to } \\
\text { some extent and also to experiential learning. More } \\
\text { typically, on-demand guidance also represents (weak) } \\
\text { learner scaffolding. This is the third of the six phases of } \\
\text { cognitive apprenticeship, following coaching. In cognitive } \\
\text { apprenticeship, on-demand support is a feature of a } \\
\text { relatively advanced stage in the learning process, when } \\
\text { direct support is diminishing and learner independence is } \\
\text { strengthening (relationship of inverse proportionality). }\end{array}$ \\
\hline $\begin{array}{l}\text { Reflection: Key } \\
\text { to learning and } \\
\text { knowing where } \\
\text { mistakes have } \\
\text { been made. }\end{array}$ & $\begin{array}{l}\text { Performance summary in preceding } \\
\text { game phase delivered to player via } \\
\text { NPC in a format befitting the game } \\
\text { scenario. Strengthens sense of } \\
\text { narrative sequence and provides } \\
\text { opportunity for self-assessment and } \\
\text { reflection on adopted game strategy. }\end{array}$ & $\begin{array}{l}\text { Reflection plays an important part in most learning } \\
\text { paradigms, especially those that tend more towards to } \\
\text { cognitivist and constructivist learning theory than to } \\
\text { behaviourism. It is a pillar of experiential learning. }\end{array}$ \\
\hline
\end{tabular}


Table 3 presents an analysis of narrative-pedagogy in the GVAB game. The table highlights the features of the NSGM and the implications it has for pedagogic practice. It also highlights the challenge posed when seeking to apply constructivism in the process of instructional design. The narrative elements encountered mainly tie the player's interactions to a specific theme and motivate the player to keep playing.

\section{WEEV - Narrative metaphor based game authoring}

The authors' current case studies as well as the works of Lindley [16], Tochon [13] and Harrell [18] all suggest that a way to bring constructivism to instructional game design is to put educators in the driving seat. This requires creating appropriate instructor-oriented game-authoring tools so they can create/adapt contents in SG.

However, most game-authoring tools and game engines (even those focused on narrative-centric genres) do not focus explicitly on designing narratives. Remarkably, most game-authoring metaphors focus solely on defining events and conditions, and the actual narrative of the game emerges by how those events are conditions are sequenced.

This represents an important challenge when trying to create NSGM, as the mechanic itself is never authored, but implied. A deeper application of NSGM requires game design and implementation processes that explicitly incorporate specific functions and capabilities for managing the narrative dimension of the authored game. This would ensure that the narrative contributes towards the learning goals by contributing to form an engaging game.

There are, however, game authoring methodologies that shift the focus towards narrative aspects. WEEV [24] is one such methodology for authoring narrative-based point-and-click educational games tool and is embodied in an authoring tool of the same name. WEEV adopts a narrative metaphor to represent game stories as interaction elements of narrative significance (i.e. story, world and actors). This untangles the story from programming aspects and renders it a unique element for specific consideration. This division foregrounds the flow of the interactive story, making it easier to co-locate the mixing of sociological ideas with semiotic epistemology.

To create a story in WEEV, the author defines the narrative flow including any accompanying puzzles, challenges and narrative elements that are central to the learning process. Although the heuristic is defined as a set of ordered steps, the WEEV methodology assumes the more realistic scenario whereby users need to revisit parts of the process as required by the unfolding of the different parts of the game. An explicit visual representation of the story is used to describe the flow of the game (Fig. 2).

The story panel contains a visual representation of the story and features a toolbar for adding new expressive elements to the story. When building a game narrative, the author works with a number of elements, including game states, user actions, effects (e.g. showing text and assessing user behaviour), and multi-interactions (i.e. two or 
three things that can be done in any order but are mandatory for moving the story along).

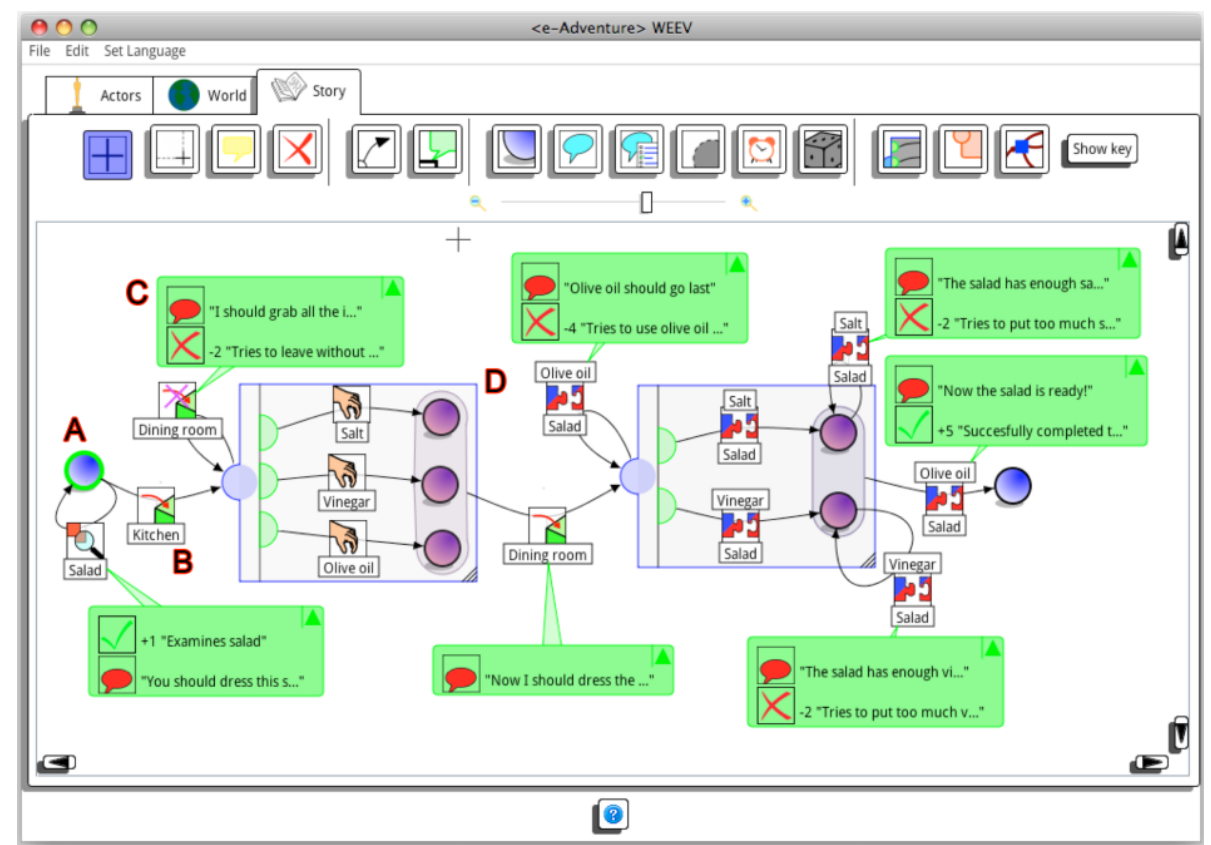

Fig. 2. WEEV story editor

Note that this authoring approach focuses solely on creating the narrative and on defining NSGM. Other game elements necessary for other serious games mechanics (such as graphics, variables, event triggers and logic conditions) are not explicitly contemplated in this stage. Instead, only after the narrative has been completely designed and refined, WEEV can generate all the internal logic required to support the narrative and offer the possibility of further editing the game to add other nonnarrative game elements.

This explicit separation of processes is also an important part of the process of increasing the focus on NSGM.

\section{Conclusions}

The Purpose/Process/Structure methodological approach has demonstrated its usefulness for identifying generic Narrative Serious Game Mechanics (NSGM) patterns. From a narrative perspective, this short study suggests that narrative in Serious Game design is so far limited to the application of narrative elements rather than drama. Drama structures narrative elements into a sequential manner so as to 
form a compelling user experience. The games that the authors have studied thus far show little evidence of dramatic structuring taking place. Instead, they incorporate narrative elements to tie the player's interactions with a specific theme and motivate the player to keep playing [25]. This in itself does not constitute a problem but it calls for further investigation as it could indicate potential gaps between practices in SG design and practices in design of related entertainment forms.

It is also important to note that the focus here is to provide insights into the narrative-pedagogical mechanism. Preliminary findings indicate that Narrative Exposition (NE) is an important storytelling tool as it is the first contact between an author and the audience. The main objectives are to introduce and represent a starting point for a drama to unfold. For this reason NE is often used as a framing device.

Narrative Guidance (NG) uses narrative elements to drive the player/protagonist to explore the SG or interact with Non-Player Characters (NPC) or fellow players. This stimulation needs to be carefully handled so that it effectively supports and enhances the learning experience, rather than eclipsing it. Similar care is required when integrating NG with the WEEV methodology because not all game elements (e.g. art resources) are easily defined within the methodology.

Reflection and feedback are an important aspect of SGs and fundamental to current theories of learning. In terms of feedback, the narrative mechanics adopted in the studied games are largely those used in entertainment video games. However, some examples have been found in which performance feedback is incorporated within the game narrative, helping the player to understand the reasons of poor/good performance.

The WEEV methodology is currently undergoing further testing in high-school English language courses. The structured approach supported by WEEV provides a framework that explicitly addresses problems that are recurrent in video game creation such as integration of the narrative with puzzles and challenges. On the forecourt of SG design the mechanics of NE, NG and Reflection can be repurposed in WEEV as reusable narrative game learning objects that contain narrative learning patterns for creating a game world and characters.

Investigations using narrative discourse are still needed to account for the contingent events that employ verbs of speech, motion, and action. The fundamental complexity in any conceptual framework/method of any postulated semiotics requires abstracting a closed system of signification to directly comprehend all its individual entities.

\section{Acknowledgments}

The work reported in this paper is co-funded under the European Community Seventh Framework Programme (FP7/2007 2013), Grant Agreement nr. 258169 and EPSRC/IMRC grant 113946. 


\section{References}

1. Propp, V.: Morphology of the Folktale. University of Texas Press. (1998) (1st English translation published 1958)

2. Campbell, J.: The hero with a thousand faces. Fontana Press. (1949)

3. Egri, L.: The Art of Dramatic Writing: It's Basis in the Creative Interpretation of Human Motives. Simon and Schuster, New York. (1942)

4. McKee, R.: Story. Methuen Publishing Ltd. (1997)

5. Vogler, C.: The Writer's Journey: Mythic Structure for Storytellers and Screenwriters. Michael Wiese Productions 3rd Ed. (2007)

6. Sheldon, L.: Character Development and Storytelling for Games. (2004)

7. Chatman, S.: Story and Discourse, narrative structure in fiction and film. Cornell University Press (1978)

8. Karagiorgi, Y., Symeou, L.: Translating Constructivism into Instructional Design: Potential and Limitations. Educational Tech. \& Soc., 8 (1) (2005) 17-27

9. Kelle, S., Klemke, R., Specht, M.: Design patterns for learning games. IJTEL, 3 (6) (2011) 555-569

10. Wexler, S., Corti, K., Derryberry, A., Quinn, C., Barneveld, A.V.: The eLearning Guild: 360 report on immersive learning simulations (2008)

11. Paetau, M.: Media technology and the structural change of knowledge societies. Proc. 7th. Intl Conf. on Sociocybernetics (2007)

12. Bateman, C. Game Writing: Narrative Skills for Videogames. Cengage Learning (2006).

13. Tochon, F.V.: Presence Beyond the Narrative: semiotic tools for deconstructing the personal story. Curriculum Studies, 2 (2) (1994) 221-247

14. Karagiorgi, Y., Symeou, L.: Translating Constructivism into Instructional Design: Potential and Limitations. Edu. Tech. \& Soc., 8 (1) (2005) 17-27

15. Labov W.: Oral narratives of personal experience. Cambridge encyclopedia of the language sciences. Cambridge, Cambridge University Press (2008)

16. Lindley, C.A: Story and Narrative Structures in Computer Games. Developing Interactive Narrative Content (2005)

17. Rosen, P.: Narrative Apparatus, Ideology. A Film Theory Reader. Columbia University Press (1986)

18. Harrell, D.A.: Theory and Technology for Computational Narrative: An Approach to Generative and Interactive Narrative with Bases in Algebraic Semiotics and Cognitive Linguistics (2007)

19. Leymore, V.L.: Hidden Myth: Structure and Symbolism in Advertising. New York: Basic Books (1975)

20. McKee, R.: Story. Methuen Publishing Ltd. (1997)

21. GoVenture AnyBusiness: www.goventureanybusiness.com/

22. Lim, T, Louchart, S, Suttie, N, Ritchie, JM., Aylett, RS., Stănescu, IA., Roceanu, I., Martinez-Ortiz, I, Moreno-Ger, P.: Strategies for Effective Digital Games Development and Implementation. In: Baek Y, Whitton N, (eds.) Cases on Digital Game-Based Learning: Methods, Models, and Strategies, pp. 168-198. IGI Global (2012)

23. Arnab S., Berta R., Earp J., De Freitas S., Romero M., Popescu M., Stanescu I., Usart M. Framing the Adoption of Serious Games in Formal Education. Electronic Journal of eLearning 01/2012 10 (2) (2012) 159-171

24. Marchiori, E.J., Torrente, J., del Blanco, Á., Moreno-Ger, P., Sancho, P., FernándezManjón, B.: A narrative metaphor to facilitate educational game authoring. Comp. \& Edu. 58 (1) (2012) $590-599$

25. Ott, M., Tavella, M. A contribution to the understanding of what makes young students genuinely engaged in computer-based learning tasks. Procedia-Social and Behavioral Sciences, 1 (1) (2009) 184-188 